\title{
Normativity and the Problem of Look in the Emergence of Citizen Journalism
}

\author{
Célestin Messanga Obama \\ Department of Advertisement, Advance School of Mass Communication, University of Yaoundé 2, Yaoundé, \\ Cameroon \\ Email: mesmobama@yahoo.fr
}

Received 6 January 2016; accepted 4 March 2016; published 9 March 2016

Copyright (C) 2016 by author and Scientific Research Publishing Inc.

This work is licensed under the Creative Commons Attribution International License (CC BY).

http://creativecommons.org/licenses/by/4.0/

c) (i)

Open Access

\begin{abstract}
Citizen journalism (in French Journalisme citoyen) is a form of journalism exercised by the public (the readers, the audiences and tele-viewers), specifically on the internet. Theoretically, it could be seen as a kind of revolution within the public getting into a trade long held jealously mainly by conventional journalists. What accounts for the fact that a trade, whose mastery requires training on its techniques and specific norms, gets invaded by untutored minds? That appears to be the central issue we are seeking to resolve in this article. We go from the hypothesis that citizen journalism has developed as a result of the publics' lack of satisfaction, both at quantitative and qualitative levels with the delivery of conventional journalism. In effect, conventional journalism raises myriad issues that require the consumers to proceed to a kind of selection, which itself could be a problem. However, by their nature, issues that constitute news are complex, and this leads to some manipulation in their treatment. These two axes appear to reveal the main sources of discord between conventional journalism and revolted-publics.
\end{abstract}

\section{Keywords}

Citizen Journalism, Conventional Journalism, Revolution, Dissatisfaction, Problematization, Normativity

\section{Introduction}

The concept of citizen journalism (in French Journalisme citoyen) may be confusing if it is understood in a civic perspective where citizen refers to "inhabitant of a city". People would see it a conventional journalism practiced with responsibility by citizens. Meanwhile, some authors (Jay Rosen, 2008; Merritt, 2015; Meyer, 2015; Dvorkin, 2015) use indifferently the expressions "public radio journalism" or "public journalism" to express the same reality. It rather appears here the idea of a journalism practiced by the public. Citizen journalism is there- 
fore a journalism especially practiced on the internet by the public of traditional media (readers, listeners or television viewers). Meanwhile, it should be noted that any speaking on the internet cannot be assimilated to citizen journalism; thus, reactions of internet users to newspaper articles considered as feedbacks to those articles cannot be considered as citizen journalism, which wants to be a daily activity of publication of social facts. In fact, public's reactions are punctual and focused not on facts but on what is said about them. We shall hereby refer to citizen journalism in the strict aspect of publication on the internet, of newspaper articles, blogs animation of websites. In this sense, even a blog animated by a journalist shall not be part of citizen journalism because that activity goes beyond the conventional frame working of journalism.

At the theoretical level, citizen journalism can be assimilated to a kind of revolution, a taking of power by the basis, in which the public takes the strong positions so far occupied by conventional journalists. What therefore explains that a job whose practice requires learning in order to master its techniques and specific norms, should be taken in charge by the uninitiated? In other words, what explains that the public decides to change the professional order, moving from their position as receivers to get the statute of senders? That is the central question to which we shall attempt to find an answer in this article.

For revolutions draws their resources from the building up of dissatisfactions of the established order, we shall say by hypothesis that citizen journalism results from dissatisfaction at the double quantitative and qualitative level of conventional journalism which is a regulative activity. For citizen journalism is considered as a form of journalism, an alter-journalism, we shall opt for the concept of “conventional journalism” to express the classical and old activity rather than the one of "professional journalism". The concept of "conventional journalism”, on the one hand, allows us to stress the normative character of journalism, and on the other hand, avoid non- productive debates on professionalism, as citizen journalism claims to be an emerging profession.

The subject of this study here is not citizen journalism itself, but the conditions of its emergence. To this effect, we shall not address issues relative to its success and shortcomings, as well as we shall not be interested in its functioning and its effects on the public.

The question of dissatisfaction in relation to conventional journalism raised in our hypothesis is also found at the quantitative level, in relation to the selection of news items (where are they from and how are they selected?) as well as at the qualitative level, in relation to logics (points of view) developed in articles published. These two major axes appear as those which are liable to reveal with ease the main sources of contention between conventional journalism and "revolted public" constituted in citizen journalists.

From the methodological point of view, this article is a qualitative analysis that is based on a corpus of 60 reactions to twelve articles from French press about war in Syria, published in Yahoo in March 2014. The newspapers studied are: Le Nouvel Observateur, L'Express, Le Pointand Libération. The choice of these four newspapers is based on their large audience and the recurrence of their publications on Yahoo. Le point and L'Express are seen as liberal oriented while the two others are socialists. The selected corpus (three articles per press organ and five reactions per article) has enabled us to identify the reasons for dissatisfaction raised by internet users. The assumption, of public's dissatisfaction, of our hypothesis locates logically our observation towards reception. These reactions, generally, are considered either as additional information, or as a problematization (calling into question) of the points of view of articles that have been read. We shall end our study by asking questions on the future of conventional journalism in this revolutionary context.

\section{Divergences Related to the Selection of Facts}

The problem of the role of journalists is built in the relation between the depicted reality they produce through their articles and the reference factual reality. An intellectual tendency considers news productions (news articles, radio and television programs) as the reflection of factual reality. Analyses, in this perspective, tend to determine the conformity among the basic facts and the reports made by journalists (the truth) or the gap (lie). In this way, media that constitute the publication framework of news productions can be classified in "truthful media" and "untruthful media". This Manichean perspective is at the basis of the problem that the role of journalists in the society poses.

However, the taking in consideration on the one hand, of the complex nature of news facts and on the other hand, the subjectivity of its apprehension, highlights a more complex reality. Jean-Pierre Esquenazi considers as error, the fact of postulating that "the media could only misrepresent or distort facts they report" (Esquenazi, 2002). He points out an important fact, that is: the discursive character of any media product. Eliseo Véron goes further when he says: "social events are not objects that could be found ready somewhere in the reality and that 
the medias would make us know the properties and the avatars afterwards with moreorless faithfulness. They only exist insofar as those media make them." (Veron, 1981). The concept of event used by Véron here is synonymous with fact.

The constructivist approach of these two authors enables to identify better the issue of citizen journalism from the activities of conventional journalists. According to Jürgen Habermas (Habermas, 1987) the fact is "the state of things that happen". In fact, many things happen in life so that one can say that "everything is a fact". Conventional journalism therefore finds itself opposite two ordeals: the one of abundance of facts and the one of quality of what is said about them.

\subsection{The Ordeal of Quantity}

The Syrian conflict is spreading out whereas old centers such as Côte-d'Ivoire, Libya, Iraq, Afghanistan and even Palestine are not yet put out. Internet users continue to draw parallels between news reports and these old facts. Such mergers bring to light two types of problems: the selection of facts and media agenda. In relation to selection, it should be noted that a priori, any fact is liable to be the subject of media coverage. Only, in their activity, journalists have a limited adequate time (the duration of an audiovisual program) and space (the page in written press or on a television screen or computer). In order to manage these time and space constraints, facing the plurality of facts, journalists must make choices. Meanwhile, on principle, any choice can be suitable for polemic. Conventional journalism has defined a number of criteria, so as to reduce this tendency for polemic, and to give an objective character to the selection of facts. They are:

- Novelty. Novelty lies in unusual fact. The current example used in most training institutions of journalists is the following: "if a dog bites a person, it is not news; news is when a person bites a dog."

- Current events. Because journalism is based on the daily reporting of facts, choice will be on the most recent events. This principle is justified by the idea according to which old facts are liable to have been published and consequently, are no longer of any interest for the public.

- Proximity. Geographical criteria that can be broken down into what professionals call "the law of kilometric death". Proximity can also be perceived at the socio-emotional level. Through this double prism, journalism gives privilege to facts which are the closest at the geographical and emotional level.

- Controversy. Controversy is based on the assumption according to which the human being is more interested in events marked by disagreement and controversy.

- Fame. Fame expresses the fact that journalism gives privilege to facts related to the life or the activity of personalities or institutions which are known (political leaders, religious and scientific authorities, stars, etc.)

- Opportunity. Opportunity refers to suitability or the pertinence of a fact in relation to context.

- Impact. Impact relates to the number of people concerned by a fact. Between two facts, the one that affects the largest number of people will be selected.

Although criteria aim at making the selection of things objective, there are nevertheless some dissatisfaction, facing a public as heterogeneous as the facts themselves and each criteria above-mentioned can be suitable for polemic. The analysis of the reactions of internet users of our corpus shows that the choice of subjects treated is one of the main causes of dissatisfaction of the public for each of the criteria mentioned above open to discussion. The wealth of facts does not only pose the problem of selection, the agenda of media also appears as an important source of dissatisfaction of the public.

\subsection{The Ordeal of the Agenda}

The criteria of selection analyzed above, suppose a free choice among facts happening at the same time. Meanwhile, Maxwell Mc Combs and Donald Shaw (McCombs et al., 1997) in their theory of agenda setting, reveal that, by putting a certain number of information on the agenda, the media dictate to the public what they must think on, even though they don't always succeed in imposing what they have to think about it. The freedom of judgment that shows through in the formula of agenda setting corroborates the problematization of reactions of the internet users analyzed. The programmatic discrepancy between the media agenda and the political agenda brought out by the two American sociologists is partly symptomatic of the quarrel created by media articles. In fact, it appears through the analysis of the corpus of our study that in reporting the constitutive facts of the Syrian crisis, the agenda of the media studied does not correspond with the expectations anti-establishment internet users. The Syrian crisis breaks out in a trouble world and regional climate. The impossibility of the media to sa- 
tisfy the different expectations paves the way for the problematisation of the agenda, the unsatisfied public being always to explain the registration or the withdrawal from the agenda of issues of their worries. It is in these lines that some people think that the media take advantage of the Syrian conflict to overshadow the "exactions" of Israel in Palestine. The problem of agenda has become worse with the appearance of agency journalism, this "common source" that has become the real prescriber of the agenda of all the media. In fact, the main transnational media, despite the large network of correspondents at their disposal, treat the same subjects at a given moment. The consequence is a kind of a unique media agenda that contributes to the reinforcement of the feeling of dissatisfaction of the public.

\section{Divergences Relative to the Processing of Facts}

Let's put aside the positivist perspective that suggests an ontological existence of facts and let's consider the constructivist approach that rather seeks the institutional and mental devices that make possible the rhetoric issuing from social actors. This perspective enables to consider the rhetoric of journalists (the news), not as the reflection of any ontological reality (the facts), but as constructs. Thus, in the process of construction their rhetoric, journalists draw inspiration as well from culture (that enables them to understand and interpret facts observed) as from their interactions with their natural and social environment. In fact, in order to understand the events that they report, journalists contact members of the society considered either as those who make facts (political actors, sportsmen in a competition, victims of an accident, etc.) or then, as witnesses who reveal facts. The professional jargon calls them "sources".

Daniel Bougnoux (2001) shows well how journalists and those sources interact in the process of construction of media discourses. The central problem here is the one of consensus between journalists and the receivers of those discourses (the public). The cooperation between journalists and the society, in the production of news is not permanent. It is a matter of punctual association during which journalists get from some members of the society, particles of facts which after transformation (processing) become news or information. Members of society, suppliers of those facts to journalists, find later on, their statute of public (listeners, readers, television viewers or internet users). The two parties remain linked by their culture that enables them to analyze the construct, thanks to the common sense that they share Jürgen Habermas (Op. cit.) talks about "the reality symbolically pre-structured". Journalists' discourse, in order to be accepted, must correspond to the interpretation that the public make of events they account for. That's the term of the consensus without which there is rejection.

The journalistic (media) truth appears when, not as correspondence with a reference ontological reality, but as correspondence with symbolic expectations of the public. The notions of truth and falsehood here take a particular signification. Is therefore true, not the newspaper article that is in accordance with any reference objective reality, but the one that responds to the public expectations. This principle is the one of selective exposure to media brought to the fore by the Americans Paul Lazarsfeld, Bernard Berelson and Hazel Gaudet (1968), according to which most people only expose themselves, in priority, to communications that agree with their previous opinions.

The problem of interpretation of facts is all the more pertinent as the protesters are not always the witnesses of the facts reported so as to have elements of reference that would enable them to appreciate the similarity or not of the disputed story. Talking about the ethics of discussion, Jürgen Habermas (Op. cit.), mentions among many others, as principle of validation of statements the consistency of arguments. It is that principle that enables interlocutors to understand each other on what makes sense or not. Such understanding supposes common standard of interpretation. Alfred Schultz (Cf. Corcuff, 1995) and many others show that the construction of common sense is done through cultural heritage, what Shultz terms "the taken for granted", that is what is accepted as truth and which, by that fact, is no longer discussed. It is generally accepted in the public opinion that politicians are liars; a newspaper article which accuses a politician of lies will be more credible than the one which pretends the contrary. Nevertheless, the public shall have only rarely reliable elements of appreciation of such allegations. Quite often, the difference of opinion constitutes the bone of contention among journalists and their public, little attention being paid to reference to facts. Thus, journalism finds itself facing the problem of look.

\subsection{The Problem of Look}

An event is empirically perceived through the senses. In this operation, a particular importance is given to the sight and the hearing. But all facts are not seen in the same manner everywhere, by all, with the same acuity. 
The object seen depends on the point from where it is seen and they talk about point of view (unique position from which they see). The point of view is not simply a geographical point; it is also a mental attitude, or to say it better, a unique cultural device of the person who sees. The look is therefore at the same time physical and cultural. It follows from this that, the fact perceived and the report made of it, are related to subjectivity that is, all that the observer has as personal, and which moreover is related to a particular context. Because the object seen depends on the subjectivity of the person who looks, discourses on facts are subjective and often problematic. This also applies to media discourse. The dissatisfactions due to the difference of points of view can explain the "revolutionary" reaction of internet users, and be the base of the emergence of citizen journalism.

As we mentioned it earlier, the process of production of news, associates journalists and public on the basis of representations of shared values. In this process, journalists try to determine the form of those values and representations. They establish themselves as opinion leaders, a role that grants them a great responsibility in relation to social peace and concord. The question of the responsibility of journalists is set at the ethical level. If it is true that Paul Lazarsfeld, Bernard Berenson and Hazel Gaudet (op. cit.) weaken the influence of the media by saying that most people expose themselves to the media that correspond to their prior opinions, they do not deny the existence of that influence. Their two step flow of communication theory (Katz Elihu \& Lazarsfeld, 1955) shows that the media have an influence on the elite who, moreover, influences the masses. Maxwell Mc Combs and Donald Shaw (Op. cit., 1997), in order to develop their theory of agenda-setting, move from the assumption according to which "if one cannot say that the media have an influence on the public, one can neither say they have no influence on the public". Moreover, it is recognized that the redundancy of media messages have an undoubted influence on opinions.

\subsection{Conventional Journalism in the Sphere of Constraints}

Journalism (the media) is generally called the fourth estate. This appellation makes people understand that there are three other powers, placed well ahead and therefore above it. In fact, this naming classifies conventional journalism after the executive, the legislative and the judiciary powers that we can bring together under the concept of "political powers". However, facing the first three which can be independent or aligned according to the systems, journalism stands as anti-establishment. Such an opposition reduces its scope of action. In fact, the first three powers provide their framework of exercise and determine the consequences in case of crossing of riding area. The respect of frame working or normativity places therefore conventional journalism in an environment of political constraints. Number of facts will thus be withdrawn from its agenda as a result of the law or several pressures. Facts which are not processed by conventional journalists because of the law constitute a source of dissatisfaction from the public which want to know about everything. The more the pressure of politicians is visible, the greater is the dissatisfaction (request to know) of the public. Such dissatisfaction could explain the emergence of citizen journalism thanks to the Internet that appears as a space out of control of politicians.

- The economic constraints are more discreet but equally heavy as political constraints. An English adage says: "Who pays owns" to say that the tone of the media is given by economico-financial powers. In fact, facing several functioning charges, and even searching material welfare, journalists are subject to the pressure of economic interests. The weight of advertisement in the media economy is well known today. In fact, beyond official contracts, advertisers who are the main sources of financing for the media impose them more or less occult conditions aiming at influencing the contents in their favor. In the same vein, the media benefit from miscellaneous subsidies. The sources of these subsidies exercise the same type of constraints as advertisers. The articles thus "manipulated" end by creating a break in relation to the public's expectations and instigate reactions aiming at "balancing" the information. Citizen journalism originates in this type of reactions.

- Cultural constraints fall within all extra-professional considerations related to the social belonging of the journalist and with which he practices. It regularly happens that journalists feel culturally involved by some media facts and adopt an editorial tone. The report made on it can instigate public dissatisfaction. In the Syrian conflict, the editorial line of the newspapers of our corpus does not stand out from the point of view of political leaders in Western Europe. Such orientations instigate disapproval reactions in the public favorable to Syrian leadership. Such breaks pave the way for what is today called citizen journalism.

\section{Normativity and Emergence of Dissent}

One could also say that the whole problem of journalism is to account for social reality, in a manner consistent 
with common values and representations, without upsetting the multiple and divergent sensibilities of the interpretative community (the public). Reaching it necessitates a good command of theoretical principles (Sciences) and know-how (techniques). We mean here the problem of training. Talking about the activity of journalists, Jean-Pierre Esquenazi says:

“...but the exercise of this mission is not an easy job. One can even say that any journalist, as soon as he starts working, finds himself immediately placed in a difficult situation. In fact, he must account for all types of differences and complications, in a single voice. For example, he explains at the same time the claims of strikers and the trade union's impossibility to satisfy them." (Op. cit. p.14)

Exceptional oratory skills are needed to reconcile in the same discourse fundamentally opposed positions. Such a talent cannot be naturally given to so many people apart from those known as journalists. This can only be obtained through learning. Training in conventional journalism thus appears as the key to success in the work of journalists. In fact, training presents a double advantage: on the one hand, it provides learners with principles and methodological tools which enable to overcome the difficulty in the practice of the job. Citizen journalism on the contrary is at odds with this training requirement. After an analysis of ten sites of citizen journalism, Tom Grubisich (2014) says that many articles in those sites lack qualities and contents, and this, despite improvements noticed. This revelation shows the importance of training in the work of journalism. Other researches on citizen journalism show that the supervision of the majority of sites of citizen journalism is carried out by conventional journalists. It appears here that you don't just suddenly become a journalist: a prior learning is necessary.

The training of journalists goes beyond the technical aspect of the job, it also touches ethics that is the moral aspect of the job. We have seen that the job of journalists aims at publishing social facts. Some of those facts are at divergent centers of interest. Professional ethics require from the journalist a balanced processing, which does neither damage nor favor a party. It is not simply a matter of reconciling different positions but a moral problem of justice that postulate equality of all before judgment. Training therefore offers journalists not only technical tools but also a moral demarcation line that makes the knife on which the equilibrium of the social balance rests.

On the other hand, training enables standardization in the practice of the job, facing multiculturality that characterizes the world. Meanwhile, such formatting creates other problems because of standardization and normativity that it instigates, in contrast with the perceptual diversity of the public. In fact, the norm, by demarcating space, restricts it and provokes contradictorily the envy to violate it (cf. the biblical myth of the forbidden fruit in the Eden garden). A look on the commentaries of the internet users, on the articles of our corpus, reveals not only a tendency to contradiction in relation to the aspects mentioned above, but also a clear will to break the norms. The different diffraction points here are on the opinions and the choice of facts actually. In short, if training is necessary for the practice of the job of journalist, it is nevertheless of a stumbling block. In fact, training tends to solve the qualitative problem of information, leaving unsatisfied the question of quantity and perceptual diversity of reality; such dissatisfaction paves the way for citizen journalism, which, itself does not escape from it.

\section{Conclusions}

Citizen journalism appears as otherness to conventional journalism. We have postulated that its emergence is caused by dissatisfaction received by conventional journalism. It appears from the preceding analysis that those dissatisfactions are at the same time of quantitative and qualitative order. As far as dissatisfaction of quantitative order is concerned, it appears that the news, subject to media coverage, is not ready made facts that journalists track down in their natural space. They are discourse on facts, that is, constructions. These constructions are achieved on the basis of numerous natural and social phenomena and this imposes a choice. If professional criteria are defined for the choice of facts, it is equally true that the public's expectations, because they are quantitatively greater, are generally unsatisfied. In fact, to each reported case, corresponds a vast number of similar cases not reported, which constitute such a lot of frustration for people involved. Citizen journalism that claims to be popular, tends, in this sense, to fill the quantitative gap of conventional journalism. The wealth of stories does not simply pose the problem of selection: it raises one of perception of facts itself. Conventional journalism functions with blinkers that reduce the visual field for each journalist as well as for each media organ, what professionals call "editorial line". Because that editorial line separates what is visible from what is not visible, it 
constitutes in fact a source of contention, because many facts cannot be seen and broadcasted. Facts which are not seen represent such a lot of points of dissatisfaction of the public who find an interest in it. In the same sense, the difference between editorial lines, according to media organs, results in variable imaginaries on the same fact.

In the light of above, it appears that by its essence, conventional journalism is at the heart of subjective issues of the society. Societies and cultures that constitute its cement being varied, it becomes difficult to construct a standard journalism with all the different sensitiveness. The deeper these differences are, the more numerous are the dissatisfactions of the public and the public's desire to fill the gaps is strong. The development of new technologies notably the Internet and mobile telephony offers in this context a fertile ground to this insurrectional practice of the public. Meanwhile, the multiplicity of facts and the divergence of points of view constitute a challenge that this insurrectional journalism can only take up. Consequently, instead of acting as a substitute for conventional journalism, citizen journalism can only consider to become a complement.

\section{References}

Bougnoux, D. (2001). Introduction aux sciences de la communication. Paris: La Découverte.

Bowman, S., \& Willis, C. (2015) We Media: How Audiences Are Shaping the Future of News and Information. In Wikipedia.

Cf. Corcuff, P. (1995). Les nouvelles sociologies. Paris: Nathan.

Dvorkin, J. A. (2015). Media Matters: Can Public Radio Journalism Be Re-Invented? In Wikipedia.

Elihu, K., \& Lazarsfeld, P. F. (1955). Personal Influence; The Part Played by People in the Flow of Mass Communications. Glencoe, ILL: Free Press.

Esquenazi, J.-P. (2002). L'écriture de l'actualité. Grenoble: PUG.

Grubisich, T. (2014). La base du journalisme: contenu reel. Quoted in the French Version of Wikipedia, 21 November 2014.

Habermas, J. (1987). Logique des sciences sociales et autres essais. Paris: PUF.

Lazarsfeld, P. F., Berelson, B., \& Gaudet, H. (1968). The People’s Choice: How the Voter Makes up His Mind in a Presidential Campaign. New York: Columbia University Press.

McCombs, M., Shaw, D. L., \& Weaver, D. H. (1997). Communication and Democracy. Taylor and Francis.

Merritt, D. (2015) News Media Must Regain Vigor, Courage. In Wikipedia.

Meyer, E. P. (2015) Public Journalism and the Problem of Objectivity. In Wikipedia.

Rosen, J. (2008). A Most Useful Definition of Citizen Journalism. In Wikipedia.

Veron, E. (1981). Construire l'évènement. Paris: Editions de Minuit, 7-8. 